\title{
Randomized Comparative Study between Direct and Indirect Tibial Revascularization in Management of Critical Limb Ischemia
}

Abdelaziz Ahmed Abdelhafez*, Omar Mokhtar Elhayeg, Hany Abd Elmomen Abdel fatah

Department of Vascular surgery, Faculty of Medicine, Al-Azhar University

*Corresponding author: Abdelaziz A Abdelhafez, Mobile: (+20)01000004564, Email: aziz4002@ hotmail.com

\begin{abstract}
Background: The importance of the angiosome concept in critical limb ischemia remains controversial. Aim of the study: to assess the outcomes of direct re-vascularization (angiosome-targeted tibial angioplasty alone) (DR) versus indirect re-vascularization (IR) non angiosome target, in isolated tibial lesions.

Patients and Methods: thirty patients were included and presented to vascular surgery department of Al-Azhar University Hospitals with infra-popliteal arterial lesions, randomly distributed into two equal groups; 15 patients was treated with (DR) while 15 patients treated with (IR).

Results: fifteen patients reached the end point of adequate healing: (9 patients with 'DR' technique and 6 patients with 'ID' technique) and 9 patients underwent major amputations. The limb salvage after one year was $70 \%$. Conclusion: direct re-vascularization (DR) of the tibial vessels appears to improve wound healing and limb salvage rates compared with IR, with no effect on patency, morbidity, mortality or re-intervention rates.

Keywords: Diabetes mellitus, critical limb ischemia, direct revascularization, indirect revascularization, angiosome.
\end{abstract}

\section{INTRODUCTION}

Peripheral arterial occlusive disease (PAOD) is a major disease that limits active aging in elderly people. Complications of PAOD are the leading cause of hospitalization and amputation for people with lower limb ischemia, and account for billion-dollar expenditures annually in the United States ${ }^{[1]}$.

Critical limb ischemia (CLI) according to the European consensus document is defined as advanced stage of chronic PAOD manifested with either: Rest pain, non-healing ulcer, gangrene and/or ankle or toe pressure of 50 or $30 \mathrm{mmHg}^{[2]}$.

CLI estimated to develop in 500 to 1000 individuals per million persons per year in the general populations. CLI has important functional implications and a major impact on the quality of life with high morbidity and mortality rates. The quality of life indices of patients with CLI have been reported to be similar to those of terminal cancer patients ${ }^{[10]}$.

Treatment goals for lower legs critical limb ischemia (CLI) patients are to increase wound healing, improve quality of life, prevent limb loss, and prolong survival ${ }^{[2]}$.

Early revascularization is the backbone modality for limb salvage in CLI. The concept of angiosomes, first described by Ian Taylor, provides practical information on the application of vascular anatomy for reconstruction ${ }^{[3]}$. Therefore, the angiosome concept suggests that recanalization of the artery that is directly supplying the ischemic and/or ulcerated angiosome, instead of revascularizing one of the other 2 major arteries might be more successful ${ }^{[4]}$.

It is unclear whether direct revascularization with the angiosome concept (DR) can provide superior results for CLI patients than that of conventional indirect revascularization (IR) without the angiosome concept ${ }^{[7]}$. There are few studies endorsing DR in CLI due to its favourable outcome compared with IR. However, other studies did not find a significant difference between DR and IR for revascularization and healing of foot ulcers to recommend DR in CLI patients. The proposed explanation for these contradicting studies is that blood flow can be restored to the foot either through inter-angiosomal choke vessel connections or through the pedal arch ${ }^{[6]}$.

However, we will perform a systematic review and meta-analysis investigating the efficacy of DR, comparing it with conventional IR for the treatment of CLI patients.

\section{PATIENTS AND METHODS}

This study included 30 patients who presented to vascular surgery department of Al-Azhar University Hospitals Cairo, Egypt with infra-popliteal arterial lesions, randomly distributed into two equal groups; 15 patients was treated with (DR) while 15 patients treated with (IR) during the period from July 2017 to June 2019.

Ethical approval and written informed consent: An approval of the study was obtained from AlAzhar University academic and ethical committee. Every patient signed an informed written consent for acceptance of the research.

\section{Inclusion criteria:}

Patients with infra inguinal arterial occlusive disease who will be diagnosed with the clinical presentations of incapacitating claudication or critical limb ischemia with angiographic confirmation of infrapopliteal lesions.

\section{Exclusion criteria:}

Patients with poor tibial collateral circulation, no target runoff. Mild claudicants or asymptomatic lesions, unsalvageable limb, acute ischemia, pregnancy, known allergy to heparin, aspirin, or other antithrombotic agents, life expectancy $<12$ months. 


\section{Clinical examination:}

At the initial clinical presentation full history was taken from every patient and the clinical data were prospectively collected regarding age, gender, risk factors and comorbidities, ABI and full details of duplex scanning, including APSV. Lesions were treated by daily dressings and followed up monthly. Post management, wound dressing protocol was standardized. Patients were followed up until they reached one of the end points of the study, which were a healed wound, a healing wound, non healing wound and major amputation. A wound was considered completely healed if it was fully covered with intact skin. It was considered adequately healing if it was completely covered with healthy granulation tissue, with absence of tissue necrosis or infection. It was considered non healed if it did not show signs of healthy granulation tissue during follow-up.

During follow-up, data were collected regarding wound status, the details of the management plan, details of duplex scanning including APSV, ABI.

\section{Statistical methodology:}

The collected data were tabulated and analyzed using statistical package for social science.

\section{Descriptive statistics:}

Number (No.), percentage (\%), mean (X. and standard deviation (SD) were determined. Significance level (P) value: $P$ value $>0.05$ was considered non-significant (NS) and $\mathrm{P}$ value $<0.05$ was considered significant (S).

\section{RESULTS}

The study included 30 patients, (18 males and 12 females) with a mean age $66.7( \pm 12.35)$. All patients were diabetic. The demographic characteristics and risk factor distribution are shown in Table (1).

Table (1): Baseline clinical characteristics of the patients

\begin{tabular}{|c|l|l|l|}
\hline \multicolumn{2}{|c|}{} & No. & Percent (\%) \\
\hline \multirow{2}{*}{ Gender } & Male & 18 & $60 \%$ \\
\cline { 2 - 4 } Age (year) & Female & 12 & $40 \%$ \\
\hline & Mean \pm SD & $66.7( \pm 12.35)$ \\
\cline { 2 - 4 } & Min. & 50 \\
\cline { 2 - 4 } & Max. & 87 \\
\hline $\begin{array}{c}\text { Ischemic heart } \\
\text { disease }\end{array}$ & Negative & 12 & $40 \%$ \\
\hline (IHD) & Positive & 18 & $60 \%$ \\
\hline $\begin{array}{c}\text { End stage renal } \\
\text { disease (ESRD) }\end{array}$ & Negative & 27 & 90 \\
\cline { 2 - 4 } $\begin{array}{c}\text { Hypertension } \\
\text { (HTN) }\end{array}$ & Positive & 3 & 10 \\
\cline { 2 - 4 } & Pegative & 12 & $40 \%$ \\
\hline \multirow{2}{*}{ Diabetes } & Negative & 18 & $60 \%$ \\
\cline { 2 - 4 } & Positive & 30 & 0 \\
\hline \multirow{2}{*}{\begin{tabular}{l} 
Smoking \\
\cline { 2 - 4 }
\end{tabular}} & Negative & 6 & 20 \\
\cline { 2 - 4 } Dyslipidaemia & Positive & 24 & 80 \\
\cline { 2 - 4 } & Pegative & 4 & 13.3 \\
\hline
\end{tabular}

Technical success occurred in 21 of PTA (70\% of all studied patients): (9 with 'DR' technique, and 12 with 'ID' technique) showing $<30 \%$ residual stenosis in 16 patients as optimal technical success and between $30-50 \%$ residual stenosis in 5 patients as suboptimal result. While 9/30 PTA (30\%) was technically failed: $6(66.7 \%)$ with 'DR' technique and $3(33.3 \%)$ with 'ID' technique.

Technical complications occurred in 12 patients (40\%): Four of them (13.3\%) developed groin haematoma, six patients (20\%) developed arterial spasm. One of them (5\%) developed flow limiting dissection and another one developed infra-popliteal thrombosis.

The primary patency rate was $(70 \%)$ at 1 and 3 months while after 6 months, was 56.7\%. and after one year, was $40 \%$

Clinical success was defined as relief of rest pain or healing of the ulcer and limb salvage, based on Rutherford categories.

Of 6 patients (20\% of all studied patients) suffering from rest pain, 4 patients $(66.7 \%)$ became asymptomatic and 2 patients $(33.3 \%)$ improved on conservative treatment. Also of 24 patients $(80 \%$ of all studied patients) suffering for minor tissue loss, 15 patients $(62.5 \%)$ reached the end point of adequate healing or complete healing: 9 patients with 'DR' technique and 6 patients with 'ID' technique) and 9 patients $(37.5 \%)$ underwent major amputations.

The limb salvage after one year was 70\% (21 patients) while the remaining 9 patients (30\%) underwent major amputation. Two patients $(6.67 \%)$ died, are shown in Figure 1.

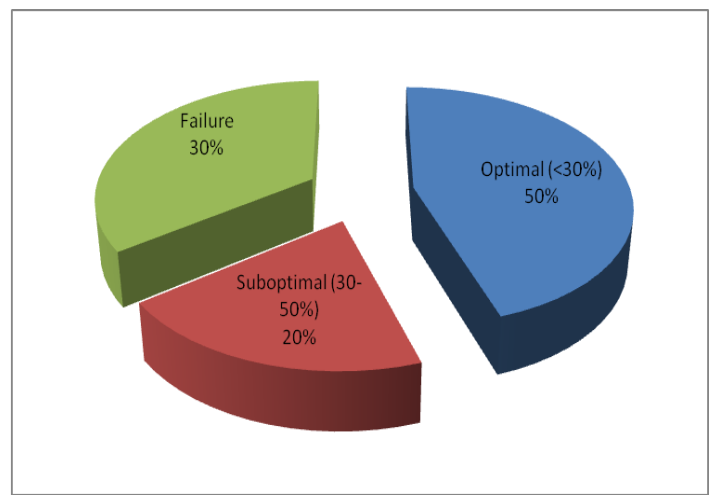

Fig. (1): Results of PTA in studied patients (Angiographic patency)

The average means APSV of the 24 limbs with healed or adequately healing lesions was significantly higher than that of the 26 limbs with non-healing lesions: $57.86 \mathrm{~cm} / \mathrm{s} \quad( \pm 12.72)$ versus $24.90 \mathrm{~cm} / \mathrm{s}$ $( \pm 9.55), p<0.001$, shown in table 2 , figure 2. 
Table 2: Comparison between patients as regard APSV

\begin{tabular}{|l|l|l|l|l|}
\hline APSV $($ mean \pm SD $)$ & \multicolumn{1}{|c|}{ Healed patients } & \multicolumn{1}{|c|}{ Non healed patients } & \multicolumn{1}{|c|}{ T-test } & P-value \\
\hline Pre & $23.04 \pm 6.51$ & $20.96 \pm 6.21$ & 1.156 & 0.253 \\
\hline After 1 week & $57.46 \pm 13.62$ & $25.00 \pm 8.91$ & 9.912 & $<\mathbf{0 . 0 0 1}$ \\
\hline After 4 weeks & $57.83 \pm 12.61$ & $24.65 \pm 11.41$ & 9.071 & $<\mathbf{0 . 0 0 1}$ \\
\hline After 8 weeks & $58.00 \pm 12.61$ & $22.65 \pm 10.41$ & 9.071 & $<\mathbf{0 . 0 0 1}$ \\
\hline After 24 weeks & $59.31 \pm 11.85$ & $23.97 \pm 10.87$ & 9.888 & $<\mathbf{0 . 0 0 1}$ \\
\hline Average APSV & $57.86 \pm 12.72$ & $24.90 \pm 9.55$ & 10.284 & $<\mathbf{0 . 0 0 1}$ \\
\hline
\end{tabular}

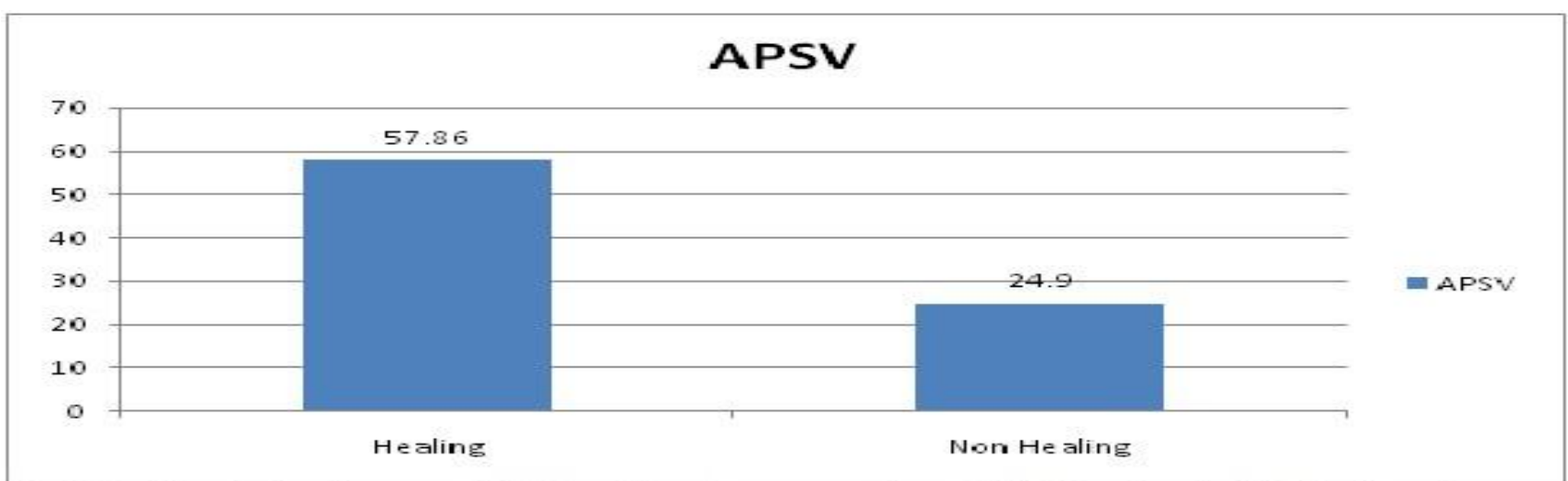

Fig.(2) : Correlation between APSV and healing , at a value of $57.86 \mathrm{~cm} / \mathrm{sec}( \pm 12.72)$ the patient healed while, at a value of $24.91 \mathrm{~cm} / \mathrm{sec}( \pm 9.55)$ the patients neither healed nor showed any progression of healing.

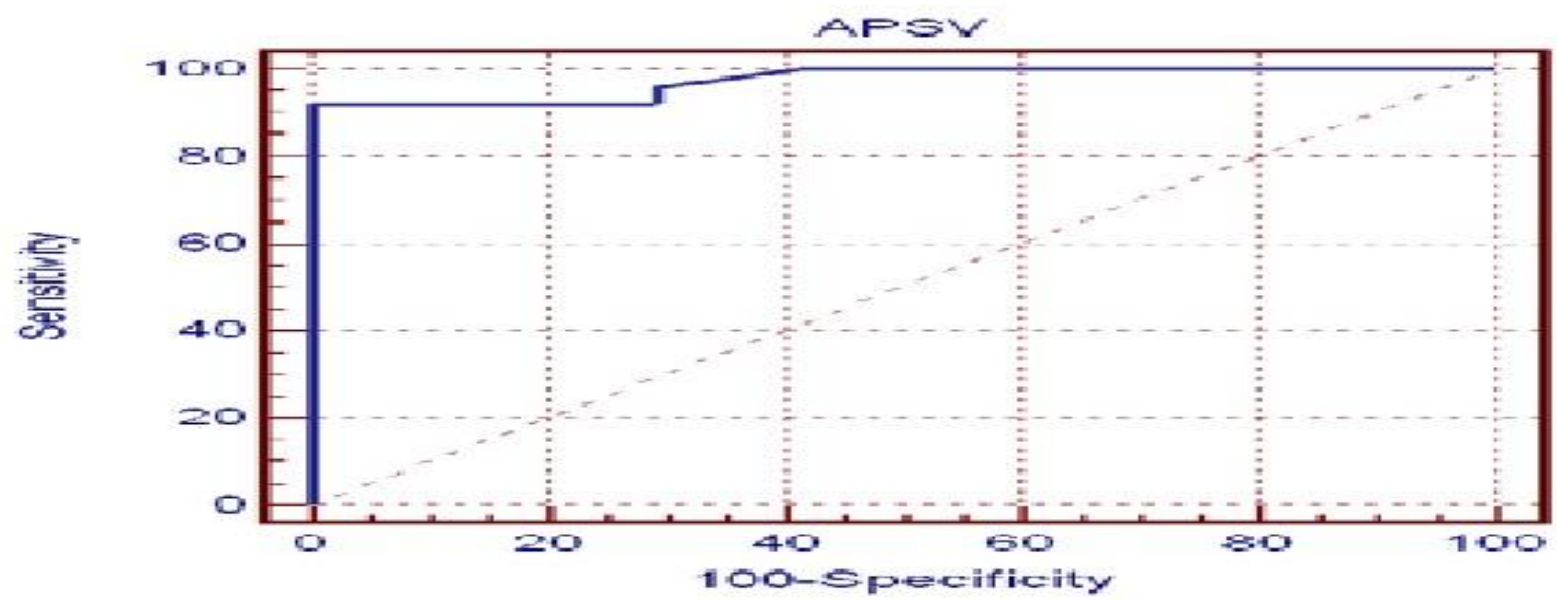

Fig.(3) : ROC curve determine the cutoff APSV value with the maximum sensitivity and specificity a cutoff value of 40 was with sensitivity of $90.91 \%$, specificity of $100 \%$, with diagnostic accuracy of $97.4 \%$ in predicting healing of diabetic foot lesions .

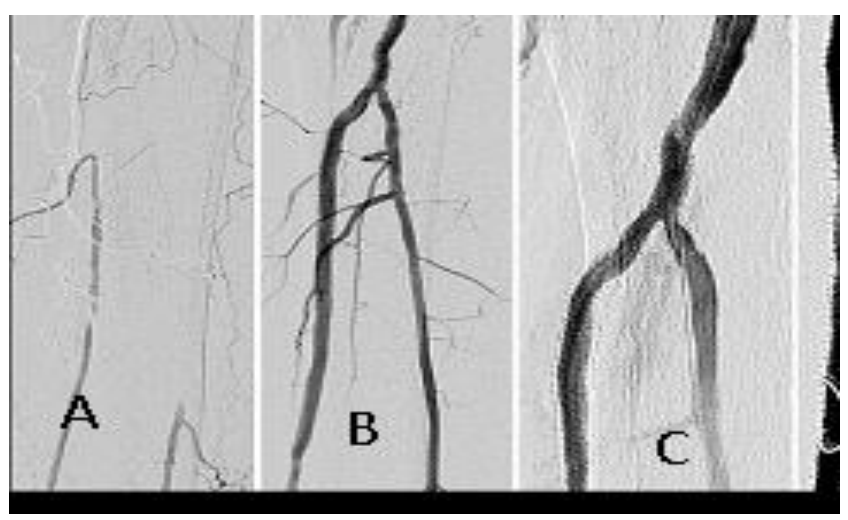

Fig. (4): An example of revascularization of the infrapopliteal arteries. (A) اين علي الرسم Baseline angiogram shows 3-vessel occlusion below the knee of 72-year-old CLI patient. (B)Completion angiogram after successful recanalization of the tibioperoneal, posterior tibial, and peroneal arteries (C) اين علي الرسم Follow-up angiogram 2 years later shows widely patent tibio-peroneal, posterior tibial, and peroneal arteries.

\section{DISCUSSION}

Effective revascularization is a cornerstone in the treatment of CLI. The angiosome anatomy had been described first by Taylor and Palme. The foot contains six angiosomes, fed by the anterior tibial artery (one angiosome), the peroneal artery (two angiosomes), and the posterior tibial artery (three angiosomes) ${ }^{[3]}$. It is unclear whether direct revascularization with the angiosome concept (DR) can provide superior results for 


\section{ejhm.journals.ekb.eg}

CLI patients than that of conventional indirect revascularization (IR) without the angiosome concept ${ }^{[7]}$.

There are studies endorsing angiosome-targeted revascularization in CLI due to more favorable outcome compared with non-angiosome-targeted angioplasty ${ }^{[4]}{ }^{[5]}$. However, other studies did not find a significant difference between angiosome-targeted and nonangiosome-targeted angioplasty for revascularization and healing of foot ulcers. The proposed explanation for these contradicting studies is that blood flow can be restored to the foot either through interangiosomal choke vessel connections or through the pedal arch ${ }^{[6]}$

However, the angiosome concept has not been systematically studied in endovascular therapy and in associated factors affecting limb salvage for CLI patients with pure, isolated tibial lesion. Our study to assess the outcomes of DR versus IR in isolated tibial lesions.

In our retrospective assessment 30 patients with critical limb ischemia having infra-popliteal arterial lesions, randomly distributed into two equal groups; (18 males and 12 females) with a mean age $66.7( \pm 12.35)$. In the present study, all 30 patients were diabetics ,18 patients (60\%) were suffering from hypertension (HTN), 24 patients were smokers $(80 \%)$ and 26 patients $(86.7 \%)$ were dyslipidaemic.

21 diabetic patients $(70 \%)$ show technical success while 9 patients $(30 \%)$ were failed. Success PTA occurred in 22 out of 26 hypertensive patients $(84.7 \%)$, $18 / 24$ of smoking patients (75\%) and $16 / 18$ of dyslipidaemic, patients $(88.9 \%)$.

The present study agrees with the results reported by Grusthat diabetes mellitus was predictive of restenosis and limb loss ${ }^{[8]}$.

In the present study, the primary technical success rate was achieved in 21 patients (70\% of all studied patients). 16 of them had optimal technical success and 5 patients had suboptimal technical success while the remaining 9 patients (30\%) had technical failure.

In the study by Stein et al., the technical success was achieved in $90 \%$ (38 out of 42 patients) ${ }^{[11]}$.

In the present study, the primary patency rate was $(70 \%)$ at 1 and 3 months while after 6 months was $56.7 \%$. and after one year was $40 \%$. Another previous study by Kabra et al., showed a higher primary patency $(88 \%)$ compared with this study ${ }^{[9]}$.

This result reflects a decline of patency rate by time, however the long-term complete patency of the treated vessels less important in such patients than in those with coronary, carotid or renal arterial disease: the re-canalization temporarily increases blood flow to the foot and has a positive effect in eradicating infection and healing ulcers and surgical wounds, thus the rate of major amputations in this study still low after 12 months of re-vascularization ${ }^{[12]}$.

\section{CONCLUSION}

DR of the tibial vessels appears to result in improved wound healing and limb salvage rates compared with
IR, with no effect on patency, morbidity, mortality or re-intervention rates. If technically feasible, dilation of angiosome target artery plus any other significant tibial artery lesions should be considered. We should orient procedures toward multiple angiosome reopening with better ulcer healing rate and limb salvage. However, with limitations and challenges of angiosome based strategies, especially in diabetic patients with depletion of choke vessels, we believe that IR should not be denied with acceptable result over the time.

\section{REFERENCES}

1. Frykberg $R$, Zgonis $T$ and Armstrong $D(2017)$ : Diabetic foot disorders: a clinical practice guideline. J Foot Ankle Surg., 45(5): 52-66.

2. Norgen L, Hiatt WR, Dormandy JA, Nehler MR, Harris KA, Fowkes FG(2007): TASC II Working Group. Inter-society consensus for the management of peripheral arterial disease (TASC II). J Vasc Surg., 45: S5-67.

3. Taylor GI, Palmer JH (1987): The vascular territories (angiosomes) of the body: experimental study and clinical applications. Br J Plast Surg., 40:113-141.

4. Neville RF, Attinger CE, Bulan EJ, Ducic I, Thomassen M, Sidawy AN (2009): Revascularization of a specific angiosome for limb salvage: does the target artery matter? Ann Vasc Surg., 23:367-373.

5. Iida $O$, Nanto $S$, Uematsu $M$, Ikeoka $K$, Okamoto $S$, Dohi Tet al. (2010): Importance of the angiosome concept for endovascular therapy in patients with critical limb ischemia. Catheter Cardiovasc Interv., 75:830-836.

6. Varela C, Acín F, de Haro J, Bleda S, Esparza L, March JR (2010): The role of foot collateral vessels on ulcer healing and limb salvage after successful endovascular and surgical distal procedures according to an angiosome model. Vasc Endovascular Surg., 44:654660 .

7. Alexandrescu V, Vincent G, Azdad K, Hubermont G, Ledent G, Ngongang C (2011): A reliable approach to diabetic neuroischemic foot wounds: below-the-knee angiosome-oriented angioplasty. J Endovascular Therapy, 18:367-387.

8. Grus T, Lukas L, Gabriela G, Peter L, Jan H, Jaroslav L (2017): Branched crural bypass has no advantage over simple crural bypass in the treatment of peripheral arterial disease, Int J Clin Exp Med., 10(5):7859-7866.

9. Kabra A, Suresh KR, Vivekanand V, Vishnu M, Sumanth R, Nekkanti M (2013): Outcomes of angiosome and non-angiosome targeted revascularization in critical lower limb ischemia. J Vasc Surg., 57:44-49.

10. Simons JP, Goodney PP, Nolan BW, Cronenwett JL, Messina LM, and Schanzer A (2010): Failure to achieve clinical improvement despite graft patency in patients undergoing infrainguinal lower extremity bypass for critical limb ischemia. Journal of Vasc Surg., 51(6): 1419-1424

11. Stein R, Hriljac I, Halperin JL et al. (2006): Limitation of the resting ankle-brachial index in symptomatic patients with peripheral arterial disease. Vasc Med., $11: 29-33$ 